\title{
Integration in Manufacturing Systems
}

\author{
Professor Krzysztof Santarek, PhD, DSc \\ Warsaw University of Technology, Faculty of Production Engineering, \\ Institute for Production Systems Organisation, 85 Narbutta Str., \\ 02-524 Warsaw, Poland, k.santarek@wip.pw.edu.pl
}

\begin{abstract}
Co-ordination of activities within an organization can be performed in a different way. One of them is system integration. In the paper a typology and features of manufacturing systems integration concepts will be discussed. Efficiency and effectiveness assessment of net-worked integrated systems for innovation development and transfer needs special approach. A concept of a new method will be introduced. The method is based on a process approach, benchmarking and involves elements of the Business Excellence Model. It can be used to conduct ex ante and ex post assessments and as a self assessment tool.
\end{abstract}

\section{Introduction}

Co-ordination of complex tasks (processes), divided between several executors (employees, organizational units) is one of basic organizational problems. An appearance of this problem was a direct consequence of the principle of work division and specialization of workers which is dated back to the first industrial revolution and is attributed to Adam Smith. Efficient and effective operation of an organization needs better co-ordination and co-operation of their elements and activities.

The importance of co-ordination is growing when products and processes are becoming more complex, organization itself, number of its workplaces and processes, external supply and distribution chains are growing too.

It is assumed that system integration is one of basic tools of co-ordination. The concept of integration means connection, joining, relationships or interdependency of elements and activities of a particular manufacturing system. It exists several ideas, approaches and means of a manufacturing systems integration. The search for more effective and efficient way of manufacturing systems integration is still an essential problem for many organizations. Some tendencies like SME's sector expansion, virtualization of enterprises, globalization of economy, popularity of outsourcing and lean manufacturing, development of supply and distribution chains are bringing about a growth of inter-organizational integration. Inter-organizational

Please use the following format when citing this chapter:

Santarek, K., 2008, in IFIP International Federation for Information Processing, Volume 257, Lean Business Systems and Beyond, Tomasz Koch, ed.; (Boston: Springer), pp. 223-230. 
integration is usually considered in a context of linking supply, manufacturing and distribution processes. Organizations more and more often are establishing complex networks dedicated to a joint R\&D projects conducting products development, their manufacturing and in some cases also product distribution, marketing and selling. Integration in this case can include all or some parts of a product life cycle.

\section{Manufacturing system decomposition}

Contemporary manufacturing systems represent complex sets of machines and technological equipment, people, control and communication devices coupled by numerous functional, technical, informational and organizational links, performing complex processes, accompanying with material, energy and information flow. Identification, design, improvements and management of these systems are extremely difficult. In a praxis it is necessary to decompose a manufacturing system into simpler elements (sub-systems) and to use suitable models for describing them.

As prof. S.Chajtman pointed out, every manufacturing system can be decomposed and fully described using only four criteria [2]. According to his concept a manufacturing system will be treated as:

- systematized set of every processes connected with material, energy and infor-mation flow and transformation, which results represent a certain value for internal or external customer,

- systematized set of distinguished system elements - assets participated in a manufacturing system operation,

- hierachically ordered set of organizational units - elements of a manufacturing system,

-- a sequence of a manufacturing system life cycle stages.

A necessary condition in order to correctly describe (identify) or design of a manufacturing system is to use at least first three criteria. Every model of a manufacturing system build according to the certain decomposition criteria will represent a specific structure, containing separate system elements and relations between them.

An original and a basic view of a manufacturing system is a structure of its all processes, their division into specific groups and relations between them. A process is a completely closed, logically and timely sequence of activities which are required to work-on process-oriented business object [1]. A general typology of processes executed in a manufacturing systems distinguish usually:

- basic, supporting and information and control (management) processes [2],

- value-added and non value-added processes (or activities).

Another example of process typology are sets (libraries) of reference models of processes, which were originally developed for process-reengineering and today are used as support in process management [3].

According to the second criterion of a manufacturing system decomposition following basic groups of a manufacturing system elements (assets) are distinguished:

- people (staff)

- machines, tools, equipment 
- materials, semi-finished products, products

- financial resources,

- information and knowledge.

Relations between them developed at the same time are specific, depending upon particular system elements.

According to third criterion a division of a manufacturing system into hierarchically ordered organizational units (production departments, functional units), produced using certain criteria are distinguished. An example can be an organizational structure (chart), layout plan, etc.

A fourth criterion of a manufacturing system decomposition will display a dynamics of a system change. Some from above mentioned changes will concern a manufacturing system as a whole as well as its specific elements (subsystems). From this perspective a manufacturing system and product life cycle can be distinguished.

Using all four criteria of a manufacturing system decomposition several (and different) manufacturing system models can be developed as a mean of manufacturing system identification. Specific models of manufacturing systems are not a subject of this paper. Concepts of manufacturing systems integration can be now derived directly from criteria of manufacturing systems decomposition.

\section{Concepts of manufacturing systems integration}

Co-ordination of activities within an organization can be achieved in different ways. One of them is integration (fig.1).

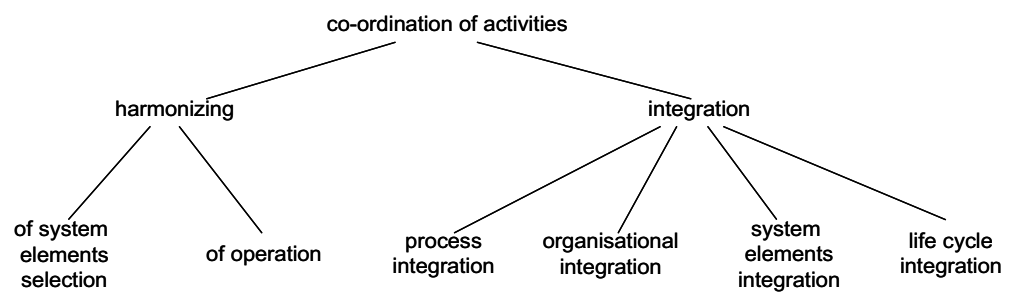

Fig. 1. Basic approaches to co-ordination of activities.

The primary kind of integration is process integration. Its results in making and in delivering products or services which fulfill client needs. Process integration gives prominence to the flow of activities in time and space. A key meaning is assigned to the integration of activities corresponding to the execution of certain production orders:

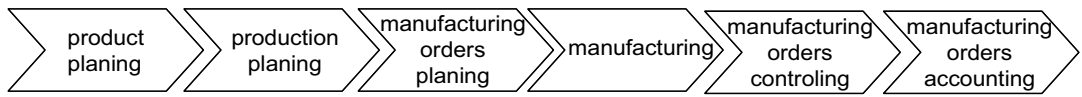

Execution of production orders requires performing not only basic (manufacturing) processes but also supporting processes (which assist and create proper conditions for performing basic processes) but also management processes, 
connected with production orders co-ordination, their planning, controlling, motivating of people, etc.

Process integration should take into consideration relations between:

- basic manufacturing processes,

- supportive manufacturing processes,

- information and control (management) processes.

Process improvement and integration are key issues in process and project management, reengineering, lean manufacturing, total quality management.

Another category is integration of workplaces (manufacturing cells, organizational units). Relations between them results from a sequence of executed by them activities which are elements of given processes. In order to control them following activities are necessary: work division, work station grouping into some larger organizational units, building an organizational hierarchy, delegation of responsibility, establishing of communication links, etc.

This kind of integration is developed when certain approach to the development of a manufacturing system structure as well as of its management is applied. Functional integration is a specific case of an integration. It is based on the involvement into manufacturing system (or an organizational unit) all necessary processes and functions connected with performing some tasks and acceptance of a certain criterion of manufa-cturing tasks (operations) and work stations (machines) grouping.

The necessity of integration concern in equal level staff (employees), manufacturing (organizational) units, processes and subsystems of an enterprise as well as other cooperating enterprises. In the first case we will deal with intra-organizational integration, in the second case - inter-organizational integration. Several reasons exists for interorganizational integration. Manufacturing and service companies, including those from distribution and trade sector, have to enter into several, different and complex relations with other companies and have to manage effectively these relations. A need of interorganizational integration grows with expansion of co-operative forms of company's operation and with the development of supply chains. Another direction of the development of inter-organizational integration is a growth of concentration forms of co-operation (eg. holdings), company's mergers and fusions, horizontal integration, etc. In every case co-operation of enterprises or their selected parts (plants, organizational units) depends to a large extent from effective and efficient co-ordination of their cooperation.

Among external factors being conducive to a development of inter-organizational integration it can enumerate: liberalization of trade, globalization of entrepreneurial activities, a growth and standardization of quality requirements, dissemination of common quality standards (eg. ISO 9000), development of information infrastructure, availability and a range of communication and information services.

Integration in manufacturing systems can concern also system elements (resources). Great importance is played by technical and social integration. Technical integration means physical (mechanical, electrical, etc.) joining of system elements: machines and other technical equipment (transport, storage, etc.). A growth of technical integration 
goes usually hand with hand with an increase of system automation. Technical integration can concern: equipment, information and data.

Equipment integration consists in a technical adjustment of technical resources, which make possible their co-operation, in particular flow of materials, energy and information streams, accompanying executed manufacturing processes. Within manufacturing systems it will concern eg. machines, transport and storage equipment, which enables an automatic transfer of loads between them.

Data integration means a possibility of using the same data in different subsystems of an enterprise, which makes necessary standardization and achievement of full conformity of its structure. Information integration means however methods and tools of data flow and control in production planning and control systems, manufacturing orders supervision, inventory, quality and costs control. At present IT is a main approach to technical integration of manufacturing systems. A manufacturing system in which all main functions are integrated on a basis of IT is called computer integrated manufacturing (CIM).

Apart from the above discussed functional and technical integration it can also distin-guish social integration. It has several dimensions: management integration, integration of functional teams of employees and organizational units, integration of users, etc. Management integration involve decision makers responsible individually or in groups for strategy at certain areas of a company, employees responsible for coordination and operational decisions eg. within PPC systems. Integration of functional teams of employees include workers linked in connection with completing jointly tasks, eg. inter-disciplinary teams of designers, task force group members, executors of complex project, etc. This form of integration is produced eg. within a concept of a process and project management and in general is connected with a team work. Information of users involve people using the same technology, treated as a specific social environment, eg. users of CAD system, operators of CNC machines, etc. Technical and social integration build together an integrated manufacturing environment.

The fourth direction of an integration of manufacturing system concern its life cycle. The significance of the integration of the manufacturing system life cycle is growing when manufacturing system should be adopted continuously to the growing and changing market conditions and match competitiveness requirements. Reduction of a lead time of innovation implementation, manufacturing costs reduction, quality improvement, global scientific and engineering progress need effective and efficient coordination of all performers and of all phases of process of the development and implementation of product, process and organizational innovation. Integration in this specific case will concern a cycle of new product development, a manufacturing system design and development or its modernization, adopting an existing system to changed external conditions. Integration of a product life cycle can involve following sequence of activities:

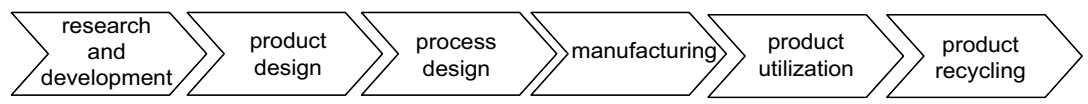

Integration of a manufacturing system life cycle will involve however: 


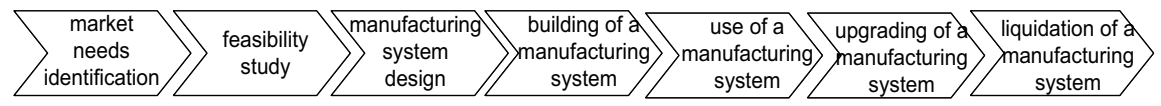

First three directions of a manufacturing system integration are linked closely each other by common:

- activities / operations which are elements of a manufacturing process, resulted as an output in products and services fulfilling certain customer needs,

- work places (stations, organizational units) at which they are performed,

- teams of workers conducted jointly certain activities at their work places.

Moreover work places are linked by a sequence of operations, common service conducted by a group of workers performing maintenance activities, $5 \mathrm{~S}$ practices, acting within quality circles, etc. Links between workers result from a joint operation of the same sequence of tasks being part of some process, which deliver certain value to internal or external customers and which need to communicate each other within certain formal or informal groups.

\section{A method of an assessment of networked organizations supporting innovation transfer}

A development and a transfer of innovations is an example of activity (process) which is often conducted within complex networks of organizations including several partners. Some examples of them are: centers of advanced technologies, centers of excellence, technology platforms, industrial clusters, regional innovation networks, industrial parks and many others. One of several problems affecting substantially the efficiency and effectiveness of innovation development and transfer within those structures is a way how activities performed by all involved partners are coordinated and integrated. Outputs of activities conducted within this structures are directed towards customers, which could be the next (subsequent) partner in this structure, building a link in an innovation process.

Therefore an assessment of these structures should involve also an efficiency and an effectiveness of the integration of all participants of an innovation process and realized by them activities (processes) which will be assumed is equivalent to the product, process or organization (manufacturing system) life cycle. The developed method enables not only an assessment of results of the innovation process (using certain criteria) but also an identification and an assessment of main (key) processes (and activities or operations as their elements) affecting significantly how innovation system operates and on results it generates. A characteristic feature of the method is an integration of an assessment of innovation system goals and its results (outputs) as well as of innovation processes (activities) divided into two stages: research and development (R\&D) and transfer of innovation. This approach enables ex post and ex ante assessment of effectiveness and efficiency of innovation systems (organizations), programs supporting innovation transfer but also innovation projects. The obtained information can support decision making. It will enable early warning and it will support implementation of certain improvements with the aim of achievement better future results (outputs). 
Main attributes of the proposed method are following:

- it is linked to an organization strategy and / or R\&D program,

- it enables a decomposition of strategic goals of an organization and/or programs into operative tasks and an assessment of their contribution in achieving strategic goals,

- it is directed towards an improvement of existing structure and/or its operation of the organization and/or program,

- it enables a self-assessment and an identification and dissemination of best practices,

- it enables relative and dynamic assessment (trend analysis, early warning),

- it is based on a reference model of innovation processes and organizations,

- it is highly flexible, it uses a diverse set of criteria, measures and processes, it can easily be adapted to different particular innovation systems, programs or projects,

- it uses a benchmarking, productivity measures and is based on process approach for innovation management and in particular on Business Excellence Model.

For the purpose of an assessment a following model of innovation transfer has been applied, Fig.2.

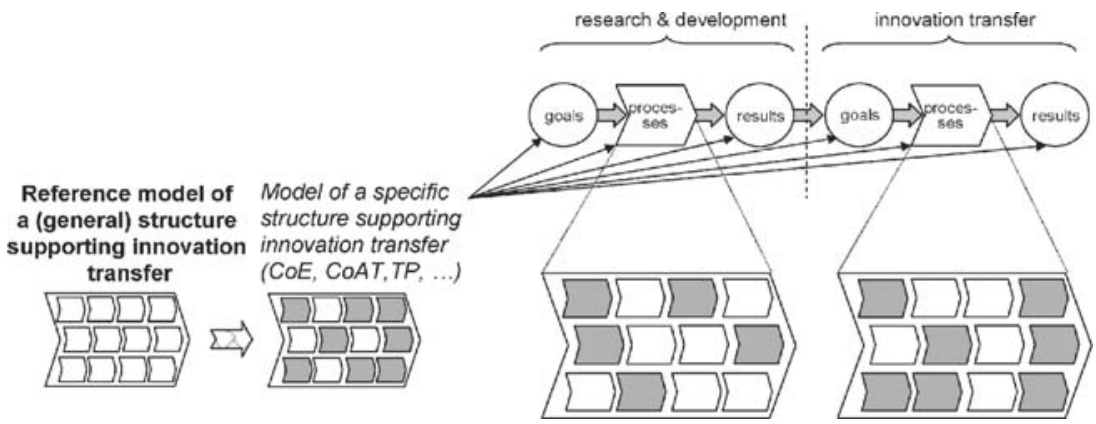

Fig. 2. A model of innovation transfer used as a basis for its assessment (simplified)

A process of an assessment includes following steps:

1. development of a model of an innovation system (program, project) to be assessed using a reference model

2. identification of goals, activities, resources and appropriate assessment measures,

3. identification of key success factors and best practices,

4. R\&D assessment

4.1. R\&D goals assessment

4.2. $R \& D$ activities assessment

4.3. R\&D results assessment

5. innovation transfer assessment

5.1. a preliminary assessment and a selection of innovation solutions to be implemented

5.2. feasibility study of the innovation transfer

5.3. an assessment of innovation transfer activities

5.4. an assessment of economic effectiveness of results of the innovation transfer 
6. analysis of assessment results, formulation of improvement suggestions and correction activities

7. implementing improvement suggestions and correction activities.

In every step the intended level of defined goals, achieved results as well as key success factors (best practices) are identified and assessed. Process (activities) assessment include process results as well as way they were obtained. A modified pattern of Business Excellens Model has been adopted.

The developed method of an assessment of innovation transfer conducted within networked structures can be used as a tool supporting the management of:

- $\quad$ innovative enterprises (incl. virtual),

- $\quad$ programs supporting technology transfer,

- $\quad$ innovative projects.

\section{Concluding remarks}

In the paper the integration as a tool for co-ordination of activities has been introduced. Based on Prof. Chajtman's concept of four dimensional decomposition of a manufacturing systems an extended model of manufacturing system integration has been proposed. A technology transfer needs mutual co-operation of all involved partners and is often realized in inter-organizational structures, what gives rise to specific problems of their integration. A new method of an assessment of innovation transfer conducted in networked structures has been introduced. Its possible application was explained using an example of an assessment of networked structures supporting technology transfer. The application of the method is a subject of extensive research conducted in different industrial research environments.

\section{References}

1. Becker J., Kugeler M., Rosemann M. (eds.), Process Management. A Guide for the Design of Business Processes, Springer-Verlag, Berlin, Heidelberg 2003.

2. Chajtman S., Information systems and processes (in Polish), PWE, Warsaw 1986.

3. Kasprzak T. (ed.), Reference models in business process management (in Polish), Difin, Warsaw 2005.

4. Santarek K., Kosieradzka A., Rafalski R., Networked structures of enterprises (in Polish), Warsaw University of Technology Publishing. Warsaw 2005.

This research was partially supported by the Ministry of Science and Informatisation within a project coordinated by the Institute of Exploitation Engineering, research grant no PW004/01/2004/3/UW-2005. 